\title{
Inhibition of Spinal 5-HT3 Receptor and Spinal Dorsal Horn Neuronal Excitability Alleviates Hyperalgesia in A Rat Model of Parkinson's Disease
}

\section{Cheng-Jie Li}

Second Affiliated Hospital of Soochow University

Lu-Bing Liu

Soochow University

Meng-Qi An

Soochow University

Li-Ge Zhang

Second Affiliated Hospital of Soochow University

\section{Li-guo Dong}

Second Affiliated Hospital of Soochow University

\section{Han-Ying Gu}

Second Affiliated Hospital of Soochow University

\section{Yong-Ping Dai}

Second Affiliated Hospital of Soochow University

Fen Wang ( $\square$ wangfen_1982@126.com )

Second Affiliated Hospital of Soochow University https://orcid.org/0000-0003-1348-7455

Cheng-Jie Mao

Second Affiliated Hospital of Soochow University

Chun-Feng Liu

Second Affiliated Hospital of Soochow University

\section{Research Article}

Keywords: Nonmotor symptoms of Parkinson's disease, Spinal dorsal horn, 5-HT3 receptor, Neuronal excitability, Hyperalgesia

Posted Date: February 25th, 2022

DOI: https://doi.org/10.21203/rs.3.rs-1377157/v1

License: (c) (1) This work is licensed under a Creative Commons Attribution 4.0 International License. Read Full License 


\section{Abstract}

Pain in Parkinson's disease (PD) is increasingly recognized as a major factor associated with poor healthrelated quality of life. However, classic therapeutic drugs supplying dopamine have limited therapeutic effect on PD related pain. This suggests that there is a mechanism outside the dopamine system that causes pain in PD. Our previous study has demonstrated that 6-OHDA induced PD model manifested hyperalgesia to thermal and mechanical stimuli and decreased serotonin (5-HT) contents in the spinal dorsal horn (SDH). Several 5-HT receptor subtypes have been confirmed to be associated with nociception in the spinal cord, such as 5-HT1A receptor, 5-HT1B receptor, 5-HT2 receptor, 5-HT3 receptor, and 5-HT7 receptor. Most researches have shown that 5-HT1A receptor and 5-HT3 receptor played a key role in pain transmission in the spinal cord. Thus, we hypothesize that hyperalgesia of 6-OHDA rats may be related to increased excitability of SDH neurons and the functional change of 5-HT3 receptor may reverse the hyperalgesia of 6-OHDA rats and decrease cell excitability of SDH neurons. To test this hypothesis, we used whole-cell patch-clamp and pharmacological methods to evaluate the effect of 5HT3 receptor and 5-HT1A receptor on the hyperalgesia of 6-OHDA rats. The results suggested that increased excitability in SDH neurons could be reversed by $5-\mathrm{HT} 3$ receptor antagonist ondansetron (20 $\mu \mathrm{mol} / \mathrm{L})$, but not 5-HT3 receptor agonist M-CPBG $(30 \mu \mathrm{mol} / \mathrm{L}), 5-\mathrm{HT} 1 \mathrm{~A}$ receptor antagonist 8-OH DPAT (10 $\mu \mathrm{mol} / \mathrm{L})$ and agonist WAY-100635 $(10 \mu \mathrm{mol} / \mathrm{L})$. Intrathecal injection with ondansetron $(0.1 \mathrm{mg} / \mathrm{kg})$ but not M-CPBG $(0.1 \mathrm{mg} / \mathrm{kg}), 8-0$ H DPAT $(0.1 \mathrm{mg} / \mathrm{kg})$ and WAY-100635 $(0.1 \mathrm{mg} / \mathrm{kg})$ significantly attenuated the mechanical hyperalgesia and thermal hyperalgesia of 6-OHDA rats. Therefore, the present study suggests that inhibition of 5-HT3 receptor relieves hyperalgesia in PD rats by reducing the excitability of SDH neurons. Our study provides a novel mechanism or therapeutic strategy for pain in patients with PD.

\section{Introduction}

Parkinson's disease (PD), the second commonest neurodegenerative disorder of the elderly, is clinically characterized by the motor symptoms of tremor, rigidity, akinesia, and dystonia. Pain as a non-motor symptom in PD is increasingly recognized as a major factor that is associated with poor health-related quality of life, even worse than motor symptoms (Chaudhuri et al. 2006). The prevalence of pain in PD patients has been reported to range from 40\%-85\% (Broen et al. 2012). According to Ford classification of pain in PD patients, there are five main subtypes of PD related pain, including musculoskeletal, dystonic, radicular, central pain and akathisia (Ford 2010). Although pain is very common in PD patients, there are no guidelines or standard remedies for the management of PD-associated pain (Antonini \& Tinazzi 2015). Therefore, it is necessary and urgent to investigate the pathogenesis of pain in PD, discovering novel and effective treatment. However, classic therapeutic drugs supplying dopamine has limited therapeutic effect on PD pain (Fil et al. 2013). This suggests that there is a mechanism outside the dopamine system that causes pain in PD.

Clinical research has demonstrated that serotonergic dysfunction was associated with pain in PD (Tong et al. 2015). Our previous study has also shown that a PD rat model induced by bilateral lesions of the substantia nigra pars compacta (SNpc) manifested hyperalgesia to thermal and mechanical stimuli and 
this hypersensitivity could be attributed at least partially to the decreased 5-HT contents in the spinal dorsal horn (SDH) (Wang et al. 2017). Whether the decreased 5-HT contents in the SDH has effect on SDH neurons requires further investigation.

Serotonin (5-HT) is one of the main neurotransmitters involved in descending inhibitory system, and its projection from the RVM to the spinal cord is thought to be related to pain modulation. Several $5-\mathrm{HT}$ receptor subtypes have been confirmed to be associated with nociception in the spinal cord, such as 5HT1A receptor, 5-HT1B receptor, 5-HT2 receptor, 5-HT3 receptor, and 5-HT7 receptor (Obata 2017).

Previous studies have demonstrated that 5-HT1A receptor, 5-HT3 receptor and 5-HT7 receptor were highly expressed in SDH and associated with nociceptive regulation (Thor et al. 1993; Tecott et al. 1993; Doly et al. 2005). Most researches have shown that 5-HT1A receptor and 5-HT3 receptor played a key role in pain transmission in the spinal cord (Bardoni 2019). 5-HT3 receptor, the only ionotropic 5-HT receptor, is a pentameric channel permeable to cations, causing the depolarization of neurons and the increase of excitability. 5-HT1A receptor is a G protein-coupled receptor, negatively coupled with adenylyl-cyclase, causing the opening of potassium channels and/or the closing of calcium channels, and inducing neuron hyperpolarization (Kim et al. 2015; Maricq et al. 1991). Therefore, the function of the 5-HT1A receptor and 5 -HT3 receptor is related to the cell excitability of the SDH neurons.

Lots of studies have shown that cell excitability of SDH neurons are increased in chronic neuropathic pain (Eide 1998). In consequence, we hypothesize that hyperalgesia of the 6-OHDA induced PD model may related to increased excitability of SDH neurons and the functional change of 5-HT3 receptor can reverse hyperalgesia of 6-OHDA rats and decrease cell excitability of SDH neurons. To test this hypothesis, we used whole-cell patch-clamp and pharmacological methods to evaluate the effect of 5HT3 receptor and

5-HT1A receptor on the hyperalgesia of the 6-OHDA PD rat model in SDH. Our study provides a novel mechanism or therapeutic strategy for pain in patients with PD.

\section{Methods}

\section{Animals}

Adult male Sprague-Dawley rats (150-180 g) were housed (five rats per cage) at a controlled temperature of $22-25^{\circ} \mathrm{C}, 40-60 \%$ relative humidity and a $12 \mathrm{~h}$ light/dark cycle with unlimited access to food and water. All experiment was approved by the Animal Use and Care Committee of Soochow University and followed the guidelines of the International Association for the Study of Pain.

\section{6-OHDA-induced a PD rat model}

Prior to surgery, rats were deeply anesthetized with isoflurane, and placed in a Stoelting stereotaxic apparatus. Perforations were slowly drilled into the skull to allow for the insertion of a $10 \mu \mathrm{L}$ Hamilton syringe, using the following stereotactic coordinates (from a rat brain atlas) $-5.3 \mathrm{~mm}$ anteroposterior, \pm 1.8 
$\mathrm{mm}$ mediolateral, and $-7.8 \mathrm{~mm}$ dorsoventral (from the dura) from the bregma. The animals were injected with $8 \mu \mathrm{g}$ 6-OHDA (dissolved in $4 \mu \mathrm{L}$ saline containing $0.02 \%$ ascorbic acid)on each side at a rate of 0.5 $\mu \mathrm{L} / \mathrm{min}$. The syringe remained in place for $8 \mathrm{~min}$ after completion of the injection, then slowly retracted. The animals were placed in a warm cage until they recover from the anesthetization and then were transferred to the animal facility (Wang et al. 2017).

\section{Behavior tests}

\section{Rotarod test}

Three weeks after surgery, the rats were subjected to a rotarod test to evaluate motor coordination and balance. Before the formal experiment, the rats were trained for three consecutive days on the rotarod system (SANS, Jiangsu Province, China) at an increasing speed (4 to $25 \mathrm{r} / \mathrm{min}$ at a rate of $0.5 \mathrm{r} / \mathrm{min}$ ). The trained rats were tested three times at a speed of $25 \mathrm{r} / \mathrm{min}$, the mean duration was recorded to analyze.

\section{Open-field test}

The open-field test was used to evaluate animals' locomotion performance and anxiety behavior. Animals were placed in a square black plank $(1 \mathrm{~m} \times 1 \mathrm{~m})$, surrounded by a $40 \mathrm{~cm}$ white wall, and divided into $25 \mathrm{x}$ $25 \mathrm{~cm}$ square by white-colored lines. Each animal was allowed to explore the box freely for $10 \mathrm{~min}$. The parameter of their behavior was recorded by the overhead camera. At the end of each trial, $75 \%$ alcohol was used to clean the box.

\section{Mechanical allodynia}

The mechanical threshold was evaluated with E-von Frey (Mgo Basile, Italy) or von Frey filaments (Aesthesio, DanMic Global, San Jose, CA, USA) using the up-down paradigm. The rats were placed in Plexiglas chambers on a wire mesh platform for 0.5-1 h. The calibrated Von Frey filaments were applied to the plantar surface of the rat hind paw with sufficient force to bend the filaments for $10 \mathrm{~s}$ or until the rat withdrew. The threshold was calculated as the force of the smallest filament causing the withdrawal behavior (Wang et al. 2015).

\section{Thermal allodynia}

The tail flick test was used to assess the thermal threshold of the animal. Radiant heat was applied to the tail using a tail flick apparatus (Mgo Basile, Italy). The radiant heat density was adjusted to yield the tail flick reaction on sham rats in 10-12 s. A cut-off of $15 \mathrm{~s}$ was set to prevent the risk of burns. The time from the laser begins to the time the animal flicks its tail was recorded as the thermal threshold to analyze.

\section{Slice preparation}

Three weeks after stereotaxic injection, the animal was anesthetized with isoflurane, decapitated, and the lumbar (L4-L6) segments were removed quickly and placed in oxygenated ice-cold Krebs solution with the 
following composition (in $\mathrm{mM}$ ): $95 \mathrm{NaCl}, 1.8 \mathrm{KCl}, 1.2 \mathrm{KH}_{2} \mathrm{PO} 4,0.5 \mathrm{CaCl}_{2}, 7 \mathrm{MgSO}, 26 \mathrm{NaHCO}_{3}, 15$ Glucose, 50 sucrose, pH7.2-7.4 (adjusted osmolarity with sucrose to $310-320 \mathrm{mOsm}$ ). The lumbar (L4L6) spinal cord was isolated, embedded in a $4 \%$ agar block and glued to the stage of the vibrating microtome. Coronal sections $(300 \mu \mathrm{m})$ were made using a vibrating microtome (Leica VT1200). Slices were incubated in oxygenated Krebs solution at $31^{\circ} \mathrm{C}$.

\section{Electrophysiology}

After incubation for $1 \mathrm{~h}$, one of the spinal cord slices was transferred to the recording grooves of nylon mesh, and the slice was fixed with a u-shaped nylon mesh. The slice at room temperature oxygenated recording liquid uniform continuous perfusion at $15 \mathrm{~mL} / \mathrm{min}$. Neurons used for recording in lamina II of spinal cord dorsal horn were visualized with an Olympus BX51WI with a 40x water-immersion objective, infrared differential interference contrast (IR)-DIC. Recordings were performed in current-clamp or voltageclamp mode at a holding potential of $-70 \mathrm{mV}$, unless otherwise indicated. The pipettes (4-8 $\mathrm{M} \Omega$ tip resistance) was filled with internal solution (in $\mathrm{mM}$ ): 133 Kgluconate, $0.6 \mathrm{EGTA}, 8 \mathrm{NaCl}, 2 \mathrm{Mg}-\mathrm{ATP}$, and 0.3 Na-GTP, 10 HEPES ( $\mathrm{pH}=7.2-7.3)$. Data were acquired using EPC10 amplifier and patchmaster software (HEKA, German), filtered and sampled at $5 \mathrm{kHz}$ with a Bessel filter amplifier. Analysis was done with Clampfit software (pClamp10, Molecular Devices, USA).

The resting potential was recorded immediately after the action potential configuration was executed. The firing patterns were evaluated using $1.5 \mathrm{~s}$ depolarizing current (step $20 \mathrm{pA}$ ) in the current clamp.

\section{Western Blotting}

Immunostaining was carried out using primary mouse anti-TH antibody (1:5000, T1299, Sigma, USA) and mouse anti- $\beta$-actin antibody (1:8000, A3854, Sigma, USA). Anti-mouse secondary antibody was used for mouse antibodies. Immunoreactive bands were obtained by clinx science instrument (Clinx, China). Densitometric analysis was performed using ImageJ software (National Institute of Health, USA).

\section{Drug Administration}

Ondansetron (03639, Sigma, USA), M-CPBG (C144, Sigma, USA), WAY-100635 (W108, Sigma, USA), and 8-OH DPAT (H8520, Sigma, USA) were purchased. For in vitro electrophysiology, the drugs, including ondansetron $(20 \mu \mathrm{mol} / \mathrm{L}), \mathrm{M}-\mathrm{CPBG}(30 \mu \mathrm{mol} / \mathrm{L})$, WAY-100635 $(10 \mu \mathrm{mol} / \mathrm{L}), 8-\mathrm{OH}$ DPAT $(10 \mu \mathrm{mol} / \mathrm{L})$ were dissolved in oxygenated ACSF to perfuse into spinal cord slices contained in chambers. The concentration of the drug used in patch clamp test is based on previous studies (Hori et al. 1996; Ito et al. 2000; Jeong et al. 2012; Xie et al. 2012; Abe et al. 2009). For behavioral tests, ondansetron $(0.1 \mathrm{mg} / \mathrm{kg})$ ,M-CPBG $(0.1 \mathrm{mg} / \mathrm{kg})$,WAY-100635 $(0.1 \mathrm{mg} / \mathrm{kg})$, and 8-OH DPAT $(0.1 \mathrm{mg} / \mathrm{kg})$ were dissolved in $0.9 \%$ normal saline and were was intrathecally injected into the L4-L6 spinal cord level of rats via a microsyringe. The rats were given persistent anesthesia with isoflurane and placed on a board with the abdomen facing down and the spine L3-L5 segments curved. The tail swing of the rats during intrathecal injection was considered successful. The drug was slowly injected and the needle was left for 
at least $30 \mathrm{~s}$ to ensure that the drug did not reflux (De la Calle \& Paíno 2002; Li et al. 2020b).The concentration of the drug used in behavioral test is based on previous studies (Eide et al. 1990; Oatway et al. 2004).

\section{Data Analyses}

Data are presented as mean \pm SEM. Statistical analysis was performed using Graphpad Prism 8 (GraphPad software, La Jolla, CA, USA). Normality was first checked for all data before analysis. Significance was determined using the Student's t-test, one-way ANOVA analysis of variance followed by Tukey's posthoc test and two-way ANOVA analysis. $P<0.05$ was considered significant.

\section{Results}

\section{Decreased mechanical and thermal pain threshold in 6-OHDA rats}

After 6-OHDA injection, we observed the behavioral phenotypes of 6-OHDA rats. The rotarod test showed less rotarod retention time in 6-OHDA rats than sham rats (Fig. 1a, ${ }^{\star}{ }^{\circ} P<0.001$, two-sample t-test) and the open field test had no difference in movement distance between 6-OHDA and sham rats from the third week after injection of 6-OHDA (Fig. 1b, $P>0.05$, two-sample t-test). Compared to sham rats, thermal pain threshold (tail-flick latency, TFL) and mechanical pain threshold (PWT) were significantly reduced in 6OHDA rats from the third week after injection of 6-OHDA (Fig. 1c-d, $* * P<0.01, * \star * P<0.001$, two-sample ttest). These behavioral test results showed that the passive movement ability of 6-OHDA rats is impaired, the active locomotion ability is normal, and the mechanical pain threshold and thermal pain threshold are reduced.

To confirm the 6-OHDA induced PD model, western blotting was used to proceed with tyrosine hydroxylase $(\mathrm{TH})$ quantification. The results showed the protein level of TH was decreased in the striatum of 6-OHDA rats (Fig. 1e-f, $P<0.01$, two-sample t-test).

\section{Classification of SDH neurons firing pattern}

Our previous study demonstrated that 5-HT contents of 6-OHDA rats are decreased in the SDH, indicating 5-HT system may be involved in hyperalgesia of 6-OHDA rats(Wang et al. 2017). In addition, as two main functional 5-HT receptors, 5-HT3 receptor and 5-HT1A receptor were related to cell excitability in the spinal cord (Kim et al. 2015; Maricq et al. 1991). Therefore, to further explore the mechanisms of 5-HT3 receptor and 5-HT1A receptor in pain hypersensitivity of 6-OHDA rats, a whole-cell patch-clamp was used to detect action potential of SDH neurons in the L4-L6 in sham rats and 6-OHDA rats. The action potential patterns of recorded neurons can be divided into four categories: tonic pattern, delayed pattern, gap pattern and single pattern. The tonic pattern is characterized by an action potential discharge that persists during the whole current step. The delayed pattern is characterized by the action potentials generating after a delay, the gap firing pattern is a response to injected depolarizing current in which an initial action potential is followed by a long inter-spike interval and then regular firing, and the single 
pattern is characterized by an action potential discharge that initiates a single spike during the whole current step (Figure. 2a).

We recorded 197 SDH neurons in the spinal cord slice from 6-8 weeks rats. In total 100 neurons from spinal cord slice of sham rats, 76 neurons exhibited a tonic pattern, 14 neurons showed a delayed pattern, 5 neurons demonstrated a gap pattern and 5 neurons showed a single pattern when current steps were applied from a membrane potential of about -70mv (Fig. 2b). Similar to the discharge classification results of the sham group, in total 97 neurons of 6-OHDA rats, 72 neurons exhibited a tonic pattern, 12 neurons showed a delayed pattern, 8 neurons demonstrated a gap pattern and 5 neurons showed a single pattern when current steps were applied from a membrane potential of about -70mv (Figure 2c). Because the vast majority of recorded neurons exhibited tonic firing patterns, we treated only tonic-type neurons, and neurons with other firing types were not included in the statistics.

\section{Increased excitability of SDH neurons in 6-OHDA rats}

Next, we compared the action potential parameters of neurons showing tonic firing pattern in the 6-OHDA group and the sham group. The resting membrane potential of neurons in 6-OHDA rats was significantly increased (Fig. 3a, $* * * P<0.001$, two-sample t-test). However, the threshold and amplitude of action potential remained unchanged compared to sham rats (Fig. 3b-c, $P>0.05$, two-sample t-test). The number of action potentials was remarkably increased under 40, 80pA current stimulation in the SDH of 6-OHDA rats compared to sham rats (Fig. $3 \mathrm{~d},{ }^{\star}{ }^{\star \star} P<0.001$, two-sample t-test). These results suggested the increased excitability of SDH neurons in 6-OHDA induced PD rat model.

\section{The effect of 5-HT3 receptor agonist and antagonist on the excitability of SDH neurons}

To examine the effect of the 5-HT3 receptor involved in the excitability of SDH neurons, action potential (AP) was recorded in the spinal cord slice in the presence of pre-and post-bath application of high efficacy 5-HT3 receptor-selective antagonist ondansetron $(20 \mu \mathrm{mol} / \mathrm{L})$ and agonist M-CPBG $(30 \mu \mathrm{mol} / \mathrm{L})$. The representative trace of typical neurons showed that bath application of ondansetron could cause a significant decrease in AP frequency in SDH neurons under 40 pA current stimulation (Fig. $4 a-b, * * P<0.01$, ${ }^{*} P<0.05$, one-way ANOVA). Furthermore, ondansetron $(20 \mu \mathrm{mol} / \mathrm{L})$ didn't significantly affect SDH neural membrane potentials both in the saline control rats and 6-OHDA rats. (Figure. $4 \mathrm{c},{ }^{*} P<0.05$, one-way ANOVA). However, the representative trace of typical neurons showed that bath application of M-CPBG $(30 \mu \mathrm{mol} / \mathrm{L})$ haven't significant effect on AP frequency in SDH neurons under $40 \mathrm{pA}$ current stimulation (Fig. 4d-e, $P>0.05$, one-way ANOVA). Similarly, M-CPBG (30 $\mu \mathrm{mol} / L)$ didn't significantly affect SDH neural membrane potentials both in the saline control rats and 6-OHDA rats (Figure $4 \mathrm{f},{ }^{\star} P<0.05$, one-way ANOVAX.

\section{The effect of 5-HT1A receptor agonist and antagonist on the excitability of SDH neurons}

We next examined the role of the 5-HT1A receptor involved in the excitability of SDH neurons through applying 5-HT1A receptor selective antagonist WAY-100635 (10 $\mu \mathrm{mol} / \mathrm{L})$ and 5-HT1A receptor agonist 8- 
OH DPAT $(10 \mu \mathrm{mol} / \mathrm{L})$ in the Krebs resolution. The representative trace of typical neurons showed that bath application of WAY-100635 $(10 \mu \mathrm{mol} / \mathrm{L})$ and 8-OH DPAT $(10 \mu \mathrm{mol} / \mathrm{L})$ haven't significant effect on AP frequency in SDH neurons under 40 pA current stimulation ( Fig. 5a,b,d,e, $P>0.05$, one-way ANOVA). WAY$100635(10 \mu \mathrm{mol} / \mathrm{L})$ and 8-OH DPAT $(10 \mu \mathrm{mol} / \mathrm{L})$ didn't significantly affect SDH neural membrane potentials both in the saline control rats and 6-OHDA rats (Figure. $5 \mathrm{c}, \mathrm{f}, * P<0.05$, one-way ANOVA).

\section{Inhibitory effect of intrathecal injection 5-HT3 receptor antagonist ondansetron but not 5-HT3 receptor agonist M-CPBG on pain hypersensitivity in 6-OHDA rats}

To investigate the role of 5-HT3 receptor in hyperalgesia of 6-OHDA rats, 4-week old rats were treated with 5 -HT3 receptor antagonist Ondansetron $(0.1 \mathrm{mg} / \mathrm{kg})$ and agonist M-CPBG $(0.1 \mathrm{mg} / \mathrm{kg})$. We found that intrathecal injection ondansetron can significantly reverse mechanical hyperalgesia and thermal hyperalgesia compared with saline control in 6-OHDA-lesioned rats (Fig. 6a-b, ${ }^{*} P<0.05, * \star P<0.01$, two-way ANOVA), while M-CPBG have little effect on hyperalgesia of 6-OHDA rats (Fig. 6c-d, $P>0.05$, two-way ANOVA). This implicated that blockade of the 5-HT3 receptor could reduce mechanical hyperalgesia and thermal hyperalgesia in 6-OHDA rats.

\section{Inhibition of spinal 5-HT1A receptor didn't relieve pain hypersensitivity in 6-OHDA rats.}

We next examined the possible pain modulatory effect of the 5-HT1A receptor in 6-OHDA rats. Surprisingly, both intrathecal injection 5-HT1A receptor agonist 8-OH DPAT $(0.1 \mathrm{mg} / \mathrm{kg})$ and antagonist WAY-100635 $(0.1 \mathrm{mg} / \mathrm{kg})$ have no effect on pain hypersensitivity in 6-OHDA lesioned rats, which indicated that 5-HT1A receptor might have nothing to do with hyperalgesia or a potential complicated mechanism involved in the pain modulatory effect of 5-HT1A receptor (Fig.7 a-d, P>0.05, two-way ANOVA).

\section{Discussion}

In the present study, 6-OHDA PD rat model induced by lesions of dopaminergic neurons in the SN developed thermal and mechanical hypersensitivity at the third week after surgery. Electrophysiological results suggested that SDH neurons had increased excitability and 5-HT3 receptor antagonist ondansetron could reversed this hyperexcitability. Intrathecal injection with 5-HT3 receptor antagonist ondansetron significantly attenuated the mechanical hyperalgesia and thermal hyperalgesia of the 6OHDA rats. To conclude, our findings suggests that inhibition of spinal 5-HT3 receptor and SDH neuronal excitability alleviates hyperalgesia of 6-OHDA rats.

According to Braak PD staging, the spinal cord can be affected in an early phase of PD(Braak et al. 2003). Clinical researches have suggested that early PD patients exhibited increased spinal nociceptive responses compared to the healthy control group (Boura et al. 2017). These studies indicated that spinal cord lesions are closely related to pain in PD. In a transgenic A53T PD model mice, a-synuclein is highly expressed in the spinal cord (Shirakashi et al. 2006) and a humanoid study shows that spinal cord stimulation alleviates motor deficits in a primate model of PD (Santana et al. 2014), which suggest that 
the spinal cord is probably a promising target for the treatment of pain in PD. Our previous study has shown that 6-OHDA rats manifested hyperalgesia to thermal and mechanical stimuli and this hypersensitivity could be attributed partially to the decreased 5-HT contents in the SDH (Wang et al. 2017). All of these give us a hint that the spinal cord and its 5-HT receptors are involved in PD-related pain, but the underlying mechanisms are still elusive.

To explore what role the spinal cord plays in pain in $\mathrm{PD}$, we investigated the electrophysiological properties of the spinal cord slice from the PD rat model. Totally, we recorded 100 neurons from sham rats and 97 neurons from 6-OHDA rats. Consistent with the previous research (Li et al. 2021), our results demonstrated that among the recorded neurons, the number of neurons exhibiting a tonic pattern is the largest (74\%-76\%). In genereal the tonic firing pattern is deem to be a hallmark of spinal inhibitory interneurons, in contrast to spinal excitatory interneurons that show delayed or gap firing patterns (Todd 2010). Moreover, the spinal inhibitory interneurons play a key role in the pain transmission in SDH. So we compared the action potential parameters of neurons showing tonic firing pattern in the 6-OHDA group and the sham group. We found that neurons with tonic firing pattern performed increased action potential frequency in the 6-OHDA rats compared with the sham rats, suggesting that these neurons transmit the higher level of nociceptive information to central nervous system. Consistently, Keri-Ann Charles et al.

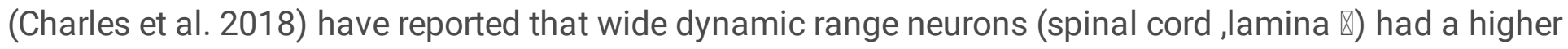
discharge frequency in 6-OHDA rats.

5-HT1 receptors, 5-HT2 receptors, 5-HT3 receptor, 5-HT7 receptors are all expressed in SDH (Doly et al. 2005; Marlier et al. 1991; Perrin et al. 2011), but 5-HT1A receptor and 5-HT3 receptor were found to exert major effect, especially in electrophysiology (Jeong et al. 2012; Fukushima et al. 2009; Abe et al. 2009). Consequently, we focused our research on 5-HT1A receptor and 5-HT3 receptor. However, we still could not rule out the role of other receptors.

Further, we explored the exact functional role of 5-HT3 receptor and 5-HT1A receptor in the hyperexcitability of SDH neurons of 6-OHDA rats. In terms of electrophysiology, we found that bath application 5-HT3 receptor antagonist ondansetron could reverse the increased cell excitability of SDH neurons. Orie Tomoyose et al have reported that Inhibition of 5-HT3 receptors inhibits excitatory synaptic transmission in the SDH, and Du jie Xu et al demonstrated that inhibition of 5-HT3 receptor alone had no significant effect on inhibitory synaptic transmission in the SDH. Thus, the inhibitory effect of ondansetron on the excitability of SDH neurons may be attributed to the attenuation of excitatory synaptic transmission.In terms of behavior tests, our results showed that intrathecal injection with ondansetron significantly attenuated the hyperalgesia of 6-OHDA rats. Consistent with our results, intrathecal administration of the 5-HT3 receptor antagonist ondansetron has been reported to inhibit spontaneous pain behaviors following intraplantar formalin injection (Chen et al. 2009) and reverse mechanical allodynia in spinal cord injury neuropathic pain model (Oatway et al. 2004; Li et al. 2020a). However, Christopher M. Peters et al have reported the lack of analgesic efficacy of spinal ondansetron on thermal nd mechanical hypersensitivity following spinal nerve igation in the rat. The possibility of 
discrepancy may be due to dual effects of 5-HT3 receptor activation on distinct population of neurons within the spinal cord dorsal horn resulting in a net lack of effect on behavioral outcomes.

The previous studies have shown that intrathecal administration of selective 5-HT3 receptor agonist (SR57,227 and M-CPBG) could alleviate hyperalgesia in spinal nerve ligation rats (Hayashida et al. 2012). Surprisingly, we found that M-CPBG didn't have obvious effect either in electrophysiological results or behavioral tests. We had tried a high concentration of M-CPBG, but still did not see a obvious effect. Several recent functional studies demonstrate that the dominant effect of 5-HT3 receptor activation in the spinal cord is anti-nociceptive by promoting GABAergic inhibitory synaptic transmission (Giordano 1991; Giordano \& Schultea 2004; Xie et al. 2012). GABA interneurons in the SDH of 6-OHDA rats may have changes in cell structure and function, resulting in the inability of M-CPBG to exert analgesic effect. Future studies are warranted to examine GABAergic system function in 6-OHDA rats.

Previous studies have shown that 8-OH-DPAT produce antinociception in carrageenan-induced inflammation and neuropathic pain model (Kim et al. 2015; Hu et al. 2016). Sagalajev et al. presented that intrathecal injection of 5-HT1A receptor antagonist WAY-100635 can reverse the hyperalgesia induction induced by high-dose glutamate application in central amygdala (Sagalajev et al. 2015). What's unusual is that our research shows that bath application or intrathecal injection WAY-100635 and 8-OHDPAT have little effect on SDH neuronal excitability and hyperalgesia in 6-OHDA lesioned rats. The dosage of the drug is selected according to previous studies (Abe et al. 2009; Jeong et al. 2012; Eide et al. 1990; Ito et al. 2000; Hori et al. 1996), but this is not probably the best dosage. The effects of higher concentrations of drugs needs to be investigated.

Jing Huang et al have indicated that the 5-HT3 receptor was expressed in the GABAergic neurons in the mouse dorsal spinal cord (Huang et al. 2008). Some researches have also reported that GABAa antagonists can reverse the antinociception effect and electrophysiologic effect of 5-HT3 receptor antagonists (Alhaider et al. 1991). It suggests that 5-HT3 receptor in the spinal cord may change the function of GABA neurons, thereby affecting the excitability of projection neurons to further exert analgesic effects. This underlying analgesic mechanism of 5-HT3 receptor needs to be further explored.

Descending pain modulation system includes serotonin system and norepinephrine system. Intrathecal injection of clonidine, an alpha 2 adrenoceptor agonist, can attenuate pain hypersensitivity in 6-OHDA lesioned PD rat model (Cao et al. 2016). Hayashida et al. demonstrate that alpha 2 adrenoceptormediated anti hypersensitivity can be weakened by the blockade of spinal 5-HT3 receptor in spinal nerve ligation rats via reduction of basal GABA tone in the spinal cord, indicating a common mechanism to reduce neuropathic pain between spinal alpha 2 adrenoceptor and 5-HT3 receptor (Hayashida et al. 2012). A potential linkage between spinal alpha 2 adrenoceptor and 5-HT3 receptor in pain regulation may exist in 6-OHDA lesioned PD rat model.

In summary, we found that inhibition of 5-HT3 receptor decreases the excitability of SDH neurons, thereby alleviating mechanical and thermal hyperalgesia in the 6-OHDA lesioned PD rat model. 


\section{Abbreviations}

SDH (spinal dorsal horn), 5-HT (serotonin), TH (Tyrosine hydroxylase), PD (Parkinson disease), AP (action potential), SNpc (substantia nigra pars compacta), L4-L6 (Fourth to sixth lumbar spinal cord).

\section{Declarations}

\section{Data Availability Statements}

The datasets generated in the current research are available from the corresponding author on reasonable request.

\section{Code availability}

Not applicable.

\section{Author contributions}

FW, CJM and CFL designed the study. CJL, LBL, MQA and LGZ performed experiments and collected data. CJL, LBL, MQA , LGD, HYG and YPD analysis and interpretation of data. CJL drafted the article, FW and CJM revised it critically for important intellectual content, FW final approvaled of the version to be submitted.

\section{Ethics approval}

This study was approved by the Animal Use and Care Committee of Soochow University and followed the guidelines of the International Association for the Study of Pain.

\section{Consent to participate}

Not applicable

\section{Consent for publication}

Not applicable

\section{Conflict of interest}

The authors declare no competing interests.

\section{Acknowledgements}

This work was supported by the National Natural Science Foundation of China (81801258), Natural Science Foundation of Jiangsu Province (BK20170355), Jiangsu Provincial social development projects (BE2018658, BE201765), Gusu Health Talents Training Project (GSWS2019041, GSWS2020035), 
Discipline Construction Program of the Second Affiliated Hospital Soochow University (XKTJ-XK202001 XKTJ-XK202004), and the Priority Academic Program Development of Jiangsu Higher Education Institutions (PAPD).

\section{References}

1. Abe, K., Kato, G., Katafuchi, T., Tamae, A., Furue, H. and Yoshimura, M. Responses to 5-HT in morphologically identified neurons in the rat substantia gelatinosa in vitro. Neuroscience.2009;159:316-324. https://doi.org/10.1016/j.neuroscience.2008.12.021

2. Alhaider, A. A., Lei, S. Z. and Wilcox, G. L. Spinal 5-HT3 receptor-mediated antinociception: possible release of GABA. J Neurosci.1991;11:1881-1888. https://doi.org/10.1523/jneurosci.11-0701881.1991

3. Antonini, A. and Tinazzi, M. Targeting pain in Parkinson's disease. The Lancet Neurology.2015;14:1144-1145. https://doi.org/10.1016/s1474-4422(15)00286-0

4. Bardoni, R. Serotonergic Modulation of Nociceptive Circuits in Spinal Cord Dorsal Horn. Curr Neuropharmacol.2019;17:1133-1145. https://doi.org/10.2174/1570159X17666191001123900

5. Boura, E., Stamelou, M., Vadasz, D., Ries, V., Unger, M. M., Kagi, G., Oertel, W. H., Moller, J. C. and Mylius, V. Is increased spinal nociception another hallmark for Parkinson's disease? J Neurol.2017;264:570-575. https://doi.org/10.1007/s00415-016-8390-y

6. Braak, H., Del Tredici, K., Rüb, U., de Vos, R. A., Jansen Steur, E. N. and Braak, E. Staging of brain pathology related to sporadic Parkinson's disease. Neurobiol Aging.2003;24:197-211. https://doi.org/10.1016/s0197-4580(02)00065-9

7. Broen, M. P., Braaksma, M. M., Patijn, J. and Weber, W. E. Prevalence of pain in Parkinson's disease: a systematic review using the modified QUADAS tool. Mov Disord.2012;27:480-484. https://doi.org/10.1002/mds.24054

8. Cao, L. F., Peng, X. Y., Huang, Y., Wang, B., Zhou, F. M., Cheng, R. X., Chen, L. H., Luo, W. F. and Liu, T. Restoring Spinal Noradrenergic Inhibitory Tone Attenuates Pain Hypersensitivity in a Rat Model of Parkinson's Disease. Neural Plast.2016;2016:6383240. https://doi.org/10.1155/2016/6383240

9. Charles, K. A., Naudet, F., Bouali-Benazzouz, R., Landry, M., De Deurwaerdere, P., Fossat, P. and Benazzouz, A. Alteration of nociceptive integration in the spinal cord of a rat model of Parkinson's disease. Mov Disord.2018;33:1010-1015. https://doi.org/10.1002/mds.27377

10. Chaudhuri, K. R., Healy, D. G. and Schapira, A. H. V. Non-motor symptoms of Parkinson's disease: diagnosis and management. The Lancet Neurology.2006;5:235-245. https://doi.org/10.1016/s14744422(06)70373-8

11. Chen, Y., Oatway, M. A. and Weaver, L. C. Blockade of the 5-HT3 receptor for days causes sustained relief from mechanical allodynia following spinal cord injury. J Neurosci Res.2009;87:418-424. https://doi.org/10.1002/jnr.21860 
12. De la Calle, J. L. and Paíno, C. L. A procedure for direct lumbar puncture in rats. Brain Res Bull.2002;59:245-250. https://doi.org/10.1016/s0361-9230(02)00866-3

13. Doly, S., Fischer, J., Brisorgueil, M. J., Vergé, D. and Conrath, M. Pre- and postsynaptic localization of the 5-HT7 receptor in rat dorsal spinal cord: immunocytochemical evidence. J Comp Neurol.2005;490:256-269. https://doi.org/10.1002/cne.20667

14. Eide, P. K. Pathophysiological mechanisms of central neuropathic pain after spinal cord injury. Spinal Cord.1998;36:601-612. https://doi.org/10.1038/sj.sc.3100737

15. Eide, P. K., Joly, N. M. and Hole, K. The role of spinal cord 5-HT1A and 5-HT1B receptors in the modulation of a spinal nociceptive reflex. Brain Res.1990;536:195-200.

https://doi.org/10.1016/0006-8993(90)90025-7

16. Fil, A., Cano-de-la-Cuerda, R., Munoz-Hellin, E., Vela, L., Ramiro-Gonzalez, M. and Fernandez-de-LasPenas, C. Pain in Parkinson disease: a review of the literature. Parkinsonism Relat Disord.2013;19:285-294; discussion 285. https://doi.org/10.1016/j.parkreldis.2012.11.009

17. Ford, B. Pain in Parkinson's disease. Mov Disord.2010;25 Suppl 1:S98-103. https://doi.org/10.1002/mds.22716

18. Fukushima, T., Ohtsubo, T., Tsuda, M., Yanagawa, Y. and Hori, Y. Facilitatory actions of serotonin type 3 receptors on GABAergic inhibitory synaptic transmission in the spinal superficial dorsal horn. $J$ Neurophysiol.2009;102:1459-1471. https://doi.org/10.1152/jn.91160.2008

19. Giordano, J. Analgesic profile of centrally administered 2-methylserotonin against acute pain in rats. Eur J Pharmacol.1991;199:233-236. https://doi.org/10.1016/0014-2999(91)90462-y

20. Giordano, J. and Schultea, T. Serotonin 5-HT(3) receptor mediation of pain and anti-nociception: implications for clinical therapeutics. Pain Physician.2004;7:141-147.

21. Hayashida, K., Kimura, M., Yoshizumi, M., Hobo, S., Obata, H. and Eisenach, J. C. Ondansetron reverses antihypersensitivity from clonidine in rats after peripheral nerve injury: role of $\gamma^{-}$ aminobutyric acid in a2-adrenoceptor and 5-HT3 serotonin receptor analgesia.Anesthesiology.2012;117:389-398. https://doi.org/10.1097/ALN.0b013e318260d381

22. Hori, Y., Endo, K. and Takahashi, T. Long-lasting synaptic facilitation induced by serotonin in superficial dorsal horn neurones of the rat spinal cord. J Physiol.1996;492 ( Pt 3):867-876. https://doi.org/10.1113/jphysiol.1996.sp021352

23. Hu, B., Doods, H., Treede, R. D. and Ceci, A. Duloxetine and 8-OH-DPAT, but not fluoxetine, reduce depression-like behaviour in an animal model of chronic neuropathic pain. Neurosci Lett.2016;619:162-167. https://doi.org/10.1016/j.neulet.2016.03.019

24. Huang, J., Wang, Y. Y., Wang, W., Li, Y. Q., Tamamaki, N. and Wu, S. X. 5-HT(3A) receptor subunit is expressed in a subpopulation of GABAergic and enkephalinergic neurons in the mouse dorsal spinal cord. Neurosci Lett.2008;441:1-6. https://doi.org/10.1016/j.neulet.2008.04.105

25. Ito, A., Kumamoto, E., Takeda, M., Shibata, K., Sagai, H. and Yoshimura, M. Mechanisms for ovariectomy-induced hyperalgesia and its relief by calcitonin: participation of 5-HT1A-like receptor on 
C-afferent terminals in substantia gelatinosa of the rat spinal cord. J Neurosci.2000;20:6302-6308. https://doi.org/10.1523/jneurosci.20-16-06302.2000

26. Jeong, H. J., Mitchell, V. A. and Vaughan, C. W. Role of 5-HT(1) receptor subtypes in the modulation of pain and synaptic transmission in rat spinal superficial dorsal horn. $\mathrm{BrJ}$ Pharmacol.2012;165:1956-1965. https://doi.org/10.1111/j.1476-5381.2011.01685.x

27. Kim, J. M., Jeong, S. W., Yang, J., Lee, S. H., Kim, W. M., Jeong, S., Bae, H. B., Yoon, M. H. and Choi, J. I. Spinal 5-HT1A, not the 5-HT1B or 5-HT3 receptors, mediates descending serotonergic inhibition for late-phase mechanical allodynia of carrageenan-induced peripheral inflammation. Neurosci Lett.2015;600:91-97. https://doi.org/10.1016/j.neulet.2015.05.058

28. Li, M., Zhu, M., Xu, Q., Ding, F., Tian, Y. and Zhang, M. Sensation of TRPV1 via 5-hydroxytryptamine signaling modulates pain hypersensitivity in a 6-hydroxydopamine induced mice model of Parkinson's disease. Biochem Biophys Res Commun.2020a;521:868-873. https://doi.org/10.1016/j.bbrc.2019.10.204

29. Li, Y., Su, S., Yu, J., Peng, M., Wan, S. and Ke, C. Electrophysiological Properties of Substantia Gelatinosa Neurons in the Preparation of a Slice of Middle-Aged Rat Spinal Cord. Front Aging Neurosci.2021;13:640265. https://doi.org/10.3389/fnagi.2021.640265

30. Li, Y. C., Tian, Y. Q., Wu, Y. Y., Xu, Y. C., Zhang, P. A., Sha, J. and Xu, G. Y. Upregulation of Spinal ASIC1 and NKCC1 Expression Contributes to Chronic Visceral Pain in Rats. Front Mol Neurosci.2020b;13:611179. https://doi.org/10.3389/fnmol.2020.611179

31. Maricq, A. V., Peterson, A. S., Brake, A. J., Myers, R. M. and Julius, D. Primary structure and functional expression of the 5HT3 receptor, a serotonin-gated ion channel. Science.1991;254:432-437. https://doi.org/10.1126/science.1718042

32. Marlier, L., Teilhac, J. R., Cerruti, C. and Privat, A. Autoradiographic mapping of 5-HT1, 5-HT1A, 5HT1B and 5-HT2 receptors in the rat spinal cord. Brain Res.1991;550:15-23. https://doi.org/10.1016/0006-8993(91)90400-p

33. Oatway, M. A., Chen, Y. and Weaver, L. C. The 5-HT3 receptor facilitates at-level mechanical allodynia following spinal cord injury. Pain.2004;110:259-268. https://doi.org/10.1016/j.pain.2004.03.040

34. Obata, H. Analgesic Mechanisms of Antidepressants for Neuropathic Pain. Int J Mol Sci.2017;18. https://doi.org/10.3390/ijms18112483

35. Perrin, F. E., Gerber, Y. N., Teigell, M., Lonjon, N., Boniface, G., Bauchet, L., Rodriguez, J. J., Hugnot, J. P. and Privat, A. M. Anatomical study of serotonergic innervation and 5-HT(1A) receptor in the human spinal cord. Cell Death Dis.2011;2:e218. https://doi.org/10.1038/cddis.2011.98

36. Sagalajev, B., Bourbia, N., Beloushko, E., Wei, H. and Pertovaara, A. Bidirectional amygdaloid control of neuropathic hypersensitivity mediated by descending serotonergic pathways acting on spinal 5HT3 and 5-HT1A receptors. Behav Brain Res.2015;282:14-24. https://doi.org/10.1016/j.bbr.2014.12.052

37. Santana, M. B., Halje, P., Simplicio, H., Richter, U., Freire, M. A. M., Petersson, P., Fuentes, R. and Nicolelis, M. A. L. Spinal cord stimulation alleviates motor deficits in a primate model of Parkinson 
disease. Neuron.2014;84:716-722. https://doi.org/10.1016/j.neuron.2014.08.061

38. Shirakashi, Y., Kawamoto, Y., Tomimoto, H., Takahashi, R. and Ihara, M. alpha-Synuclein is colocalized with 14-3-3 and synphilin-1 in A53T transgenic mice. Acta Neuropathol.2006;112:681689. https://doi.org/10.1007/s00401-006-0132-2

39. Tecott, L. H., Maricq, A. V. and Julius, D. Nervous system distribution of the serotonin 5-HT3 receptor mRNA. Proc Natl Acad Sci U S A.1993;90:1430-1434. https://doi.org/10.1073/pnas.90.4.1430

40. Thor, K. B., Nickolaus, S. and Helke, C. J. Autoradiographic localization of 5-hydroxytryptamine1A, 5hydroxytryptamine1B and 5-hydroxytryptamine1C/2 binding sites in the rat spinal cord.

Neuroscience.1993;55:235-252. https://doi.org/10.1016/0306-4522(93)90469-v

41. Todd, A. J. Neuronal circuitry for pain processing in the dorsal horn. Nat Rev Neurosci.2010;11:823836. https://doi.org/10.1038/nrn2947

42. Tong, Q., Zhang, L., Yuan, Y. et al. Reduced plasma serotonin and 5-hydroxyindoleacetic acid levels in Parkinson's disease are associated with nonmotor symptoms. Parkinsonism Relat Disord.2015;21:882-887. https://doi.org/10.1016/j.parkreldis.2015.05.016

43. Wang, C. T., Mao, C. J., Zhang, X. Q. et al. Attenuation of hyperalgesia responses via the modulation of 5-hydroxytryptamine signalings in the rostral ventromedial medulla and spinal cord in a 6hydroxydopamine-induced rat model of Parkinson's disease. Mol Pain.2017;13:1744806917691525. https://doi.org/10.1177/1744806917691525

44. Wang, Q., Zhu, H., Zou, K., Yuan, B., Zhou, Y. L., Jiang, X., Yan, J. and Xu, G. Y. Sensitization of P2X3 receptors by cystathionine $\beta$-synthetase mediates persistent pain hypersensitivity in a rat model of lumbar disc herniation. Mol Pain.2015;11:15. https://doi.org/10.1186/s12990-015-0012-7

45. Xie, D. J., Uta, D., Feng, P. Y., Wakita, M., Shin, M. C., Furue, H. and Yoshimura, M. Identification of 5-HT receptor subtypes enhancing inhibitory transmission in the rat spinal dorsal horn in vitro. $\mathrm{Mol}$ Pain.2012;8:58. https://doi.org/10.1186/1744-8069-8-58

\section{Figures}


a
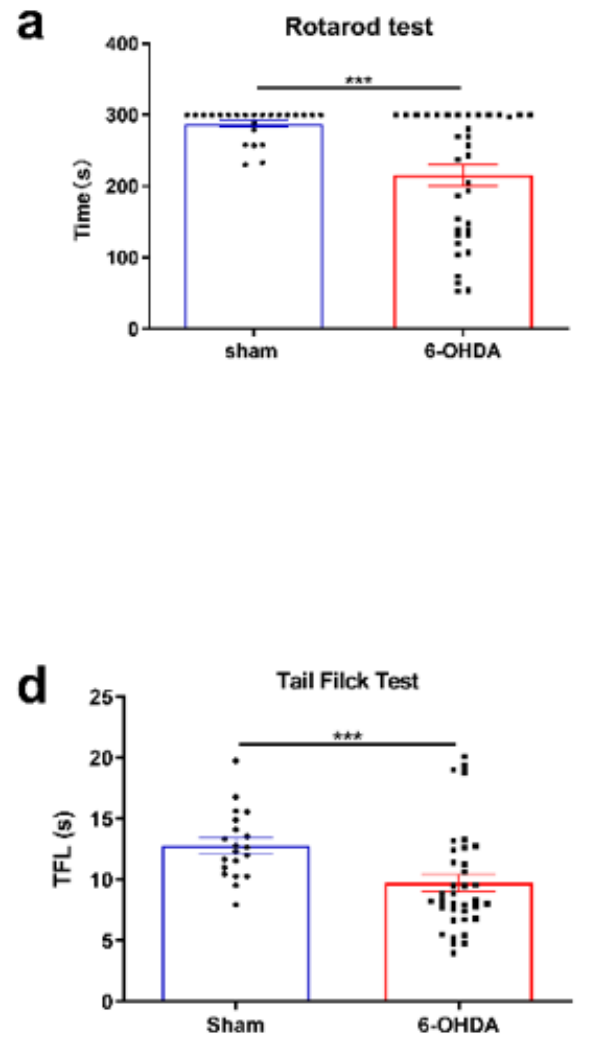

b
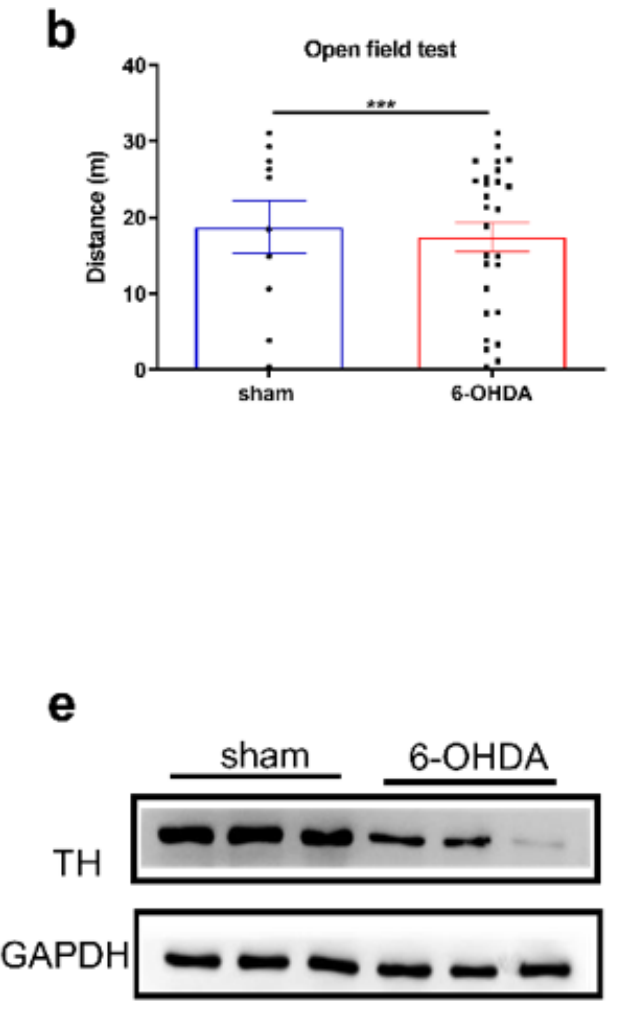

C

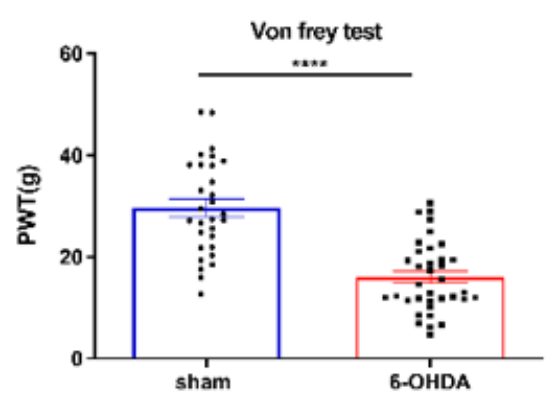

f

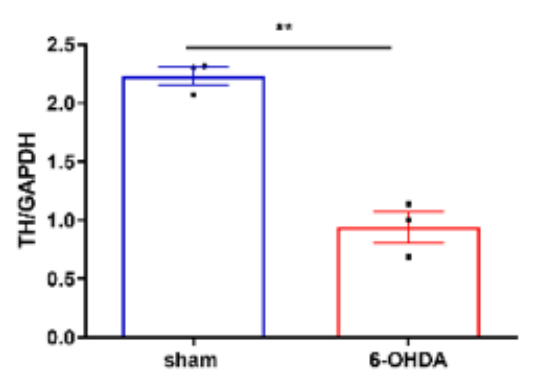

\section{Figure 1}

Reduction in thermal and mechanical thresholds in 6-OHDA-treated rats

a, The passive movement performance is significantly decreased in 6-OHDA treated rats compared to sham-treated rats. ( $\mathrm{n}=25$ for each group, ${ }^{\star \star \star} P<0.001$, two-sample t-test).

b, The locomotion activity performance is unimpaired in 6-OHDA treated rats compared to sham-treated rats. ( $n=10$ for sham rats and $n=27$ for 6 -OHDA rats, $P>0.05$, two-sample t-test).

c, Paw withdrawal threshold in von frey test is notably reduced in 6-OHDA treated rats compared to shamtreated rats. ( $\mathrm{n}=30$ for each group, $* \star \star P<0.001$, two-sample t-test).

$\mathrm{d}$, The latency time in the tail-flick test is remarkably decreased in 6-OHDA treated rats compared to shamtreated rats. ( $\mathrm{n}=20$ for sham rats and $\mathrm{n}=46$ for 6 -OHDA rats, $\star \star * P 0.01$, two-sample t-test).

e-f, The expression level of tyrosine hydroxylase $(\mathrm{TH})$ in the striatum was revealed by western

blotting. The bottom bar graph showed the relative density of TH/GAPDH between the 6-OHDA-treated group and the sham group ( $\mathrm{n}=3$ for each group, ${ }^{\star \star} P<0.01$, two-sample t-test). 
a

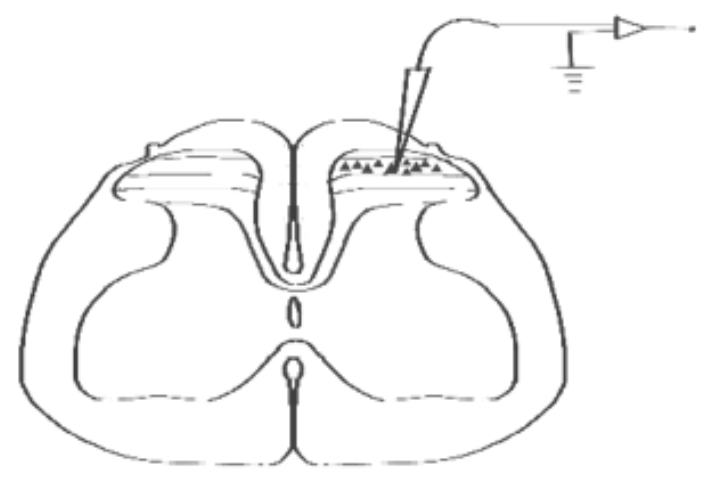

Tonic

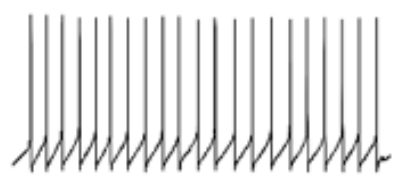

Single

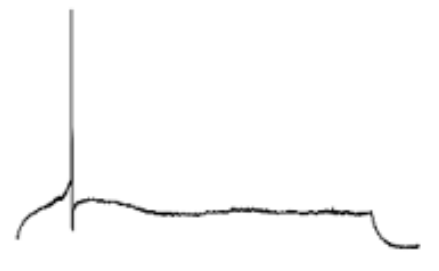

Gap

Delayed b

Firing pattern of sham rats

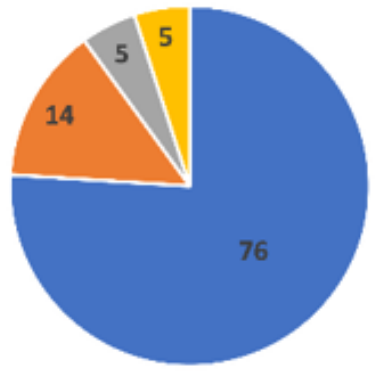

- tonic = delayed " gap " single

C
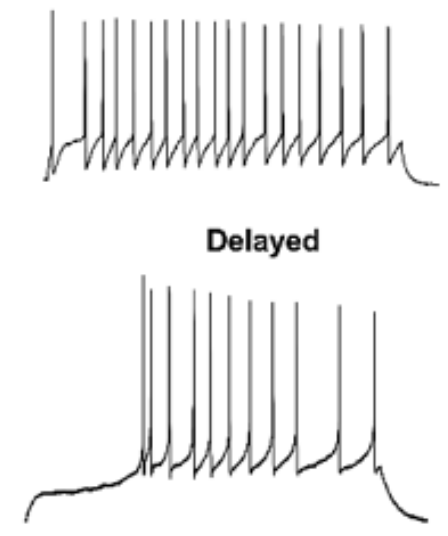

$50 \mathrm{mv}$
Firing pattern of 6-OHDA rats

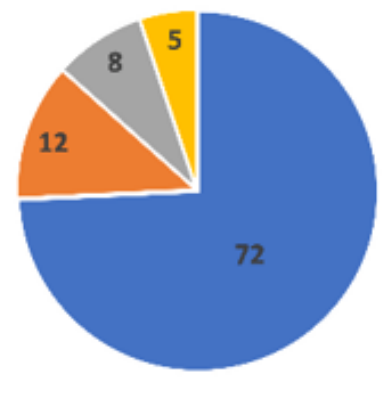

- tonic = delayed " gap " single

200ms

\section{Figure 2}

Discharge patterns observed in SDH neurons

a, Sample current clamp recordings obtained from SDH neurons, by holding the membrane potential at $-70 \mathrm{mV}$. The typical races for each firing pattern. Scale Bar: 10mV, $200 \mathrm{~ms}$.

b, The number of neurons exhibiting the different firing types, from a total sample of 100 SDH neurons in sham rats.

c, The number of neurons exhibiting the different firing types, from a total sample of $97 \mathrm{SDH}$ neurons in 6-OHDA rats. 
a

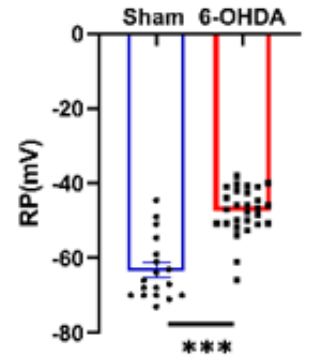

d

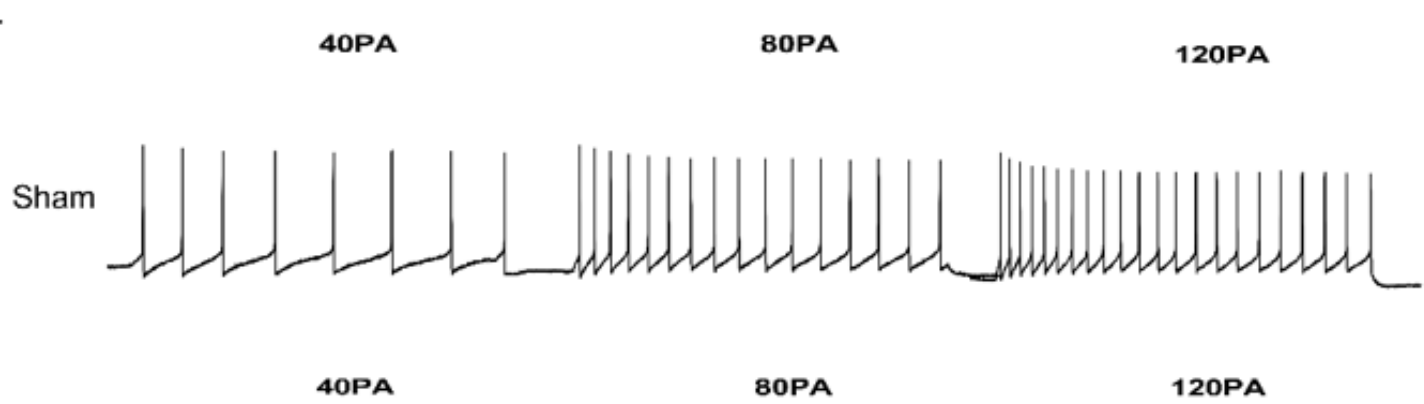

b

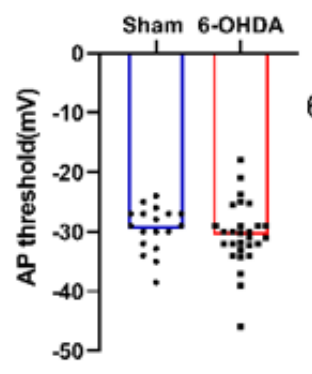

C

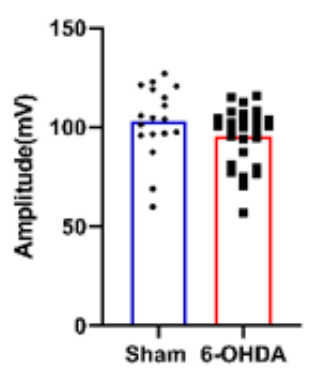

\section{Figure 3}

6-OHDA rats showed enhanced neuronal excitability compared to sham rats.

a, 6-OHDA rats exhibited a more depolarized resting membrane potential than sham rats. ( $n=18$ cells for sham rats and $n=28$ cells for $6-0 H D A$ rats, $* * * P<0.001$, two-sample t-test).

b-c, No significant difference in action potential threshold and amplitude of action potential was observed between $6-0$ HDA rats and sham rats. $(n=18$ cells for sham rats and $n=28$ cells for $6-0 H D A$ rats, $P>0.05$, two-sample t-test).

d, The number of action potentials dramatically increased under 40 and 80 ramps current stimulation in 6-OHDA rats. ( $n=18$ cells for sham rats and $n=28$ cells for $6-0 H D A$ rats, ${ }^{\star \star \star} P<0.001$, two-sample t-test).

\section{Figure 4}

The effect of 5-HT3 receptor agonist and antagonist on the excitability of SDH neurons 
a, Representative current-clamp recordings showing firing evoked by $40 \mathrm{pA}$ current injection from an SDH neuron of a saline control rat (left panels) and that from an SDH neuron of a 6-OHDA-lesioned rat (right panels) in the absence (upper panels) and presence (middle panels) of ondansetron (20 $\mu \mathrm{M})$

b,Ondansetron significantly reduces AP frequency recorded in the SDH neurons of sham and 6-OHDA rats at L4-L6. ( $\mathrm{n}=8$ cells for sham rats and $\mathrm{n}=9$ cells for 6 -OHDA rats, ${ }^{*} P<0.01, * P<0.05$, one-way ANOVA).

c, Summarized data showing the mean resting membrane potential of the SDH neurons in the saline control rats and the $6-\mathrm{OHDA}$-lesioned rats with and without ondansetron. $(\mathrm{n}=8$ cells for sham rats and $\mathrm{n}=9$ cells for $6-\mathrm{OHDA}$ rats, ${ }^{*} P<0.05$, one-way ANOVA).

d, Representative current-clamp recordings showing firing evoked by $40 \mathrm{pA}$ current injection from an SDH neuron of a saline control rat (left panels) and that from an SDH neuron of a 6-OHDA-lesioned rat (right panels) in the absence (upper panels) and presence (middle panels) of M-CPBG (30 $\mu \mathrm{M})$

e, M-CPBG have no significant effect on AP frequency recorded in the SDH neurons of sham and 6-OHDA rats at L4-L6. ( $n=8$ cells for sham rats and $n=10$ cells for $6-O H D A$ rats, $P>0.05$, one-way ANOVA).

$\mathrm{f}$, Summarized data showing the mean resting membrane potential of the SDH neurons in the saline control rats and the 6-OHDA-lesioned rats with and without M-CPBG. $(n=8$ cells for sham rats and $n=10$ cells for 6-OHDA rats, ${ }^{*} P<0.05$, one-way ANOVA). 
a Saline

6-OHDA

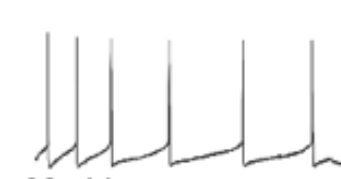

$-62 m V$

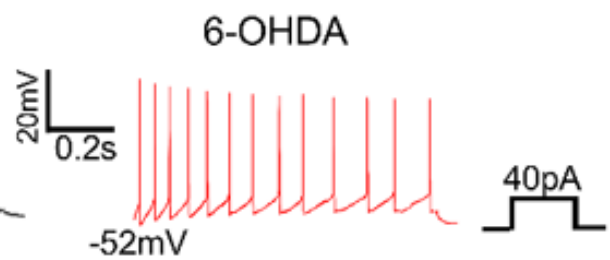

d
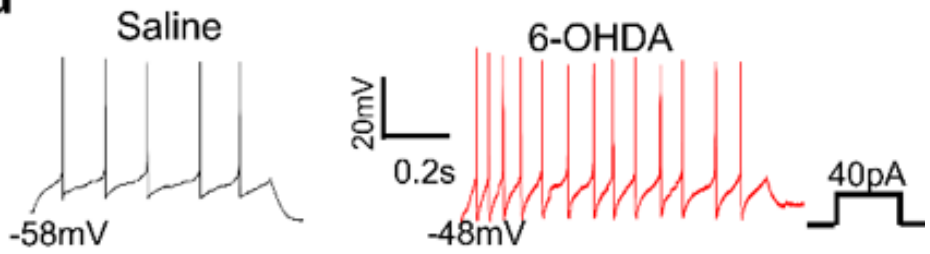

Saline+WAY-100635 6-OHDA+WAY-100635

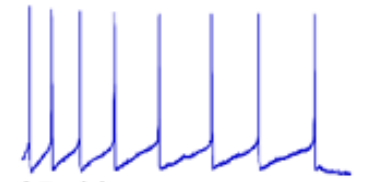

$-65 \mathrm{mV}$
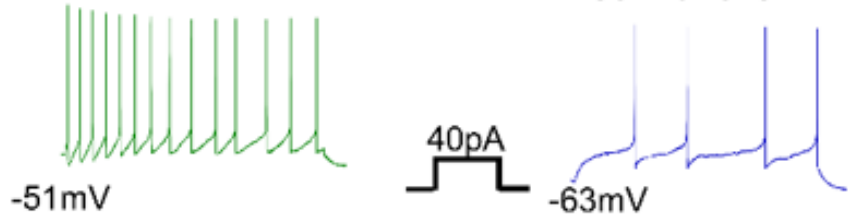

Saline+8-OH DPAT

b

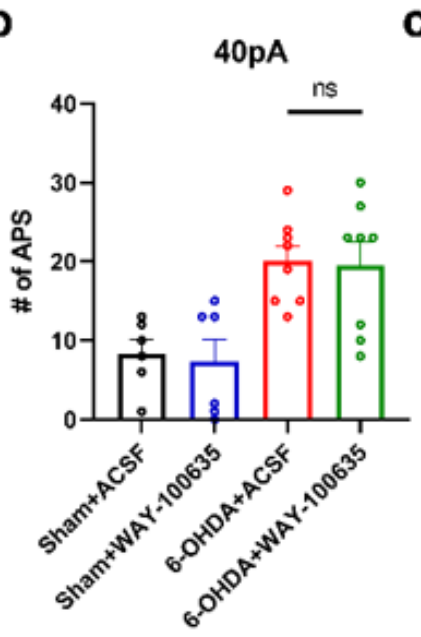

C
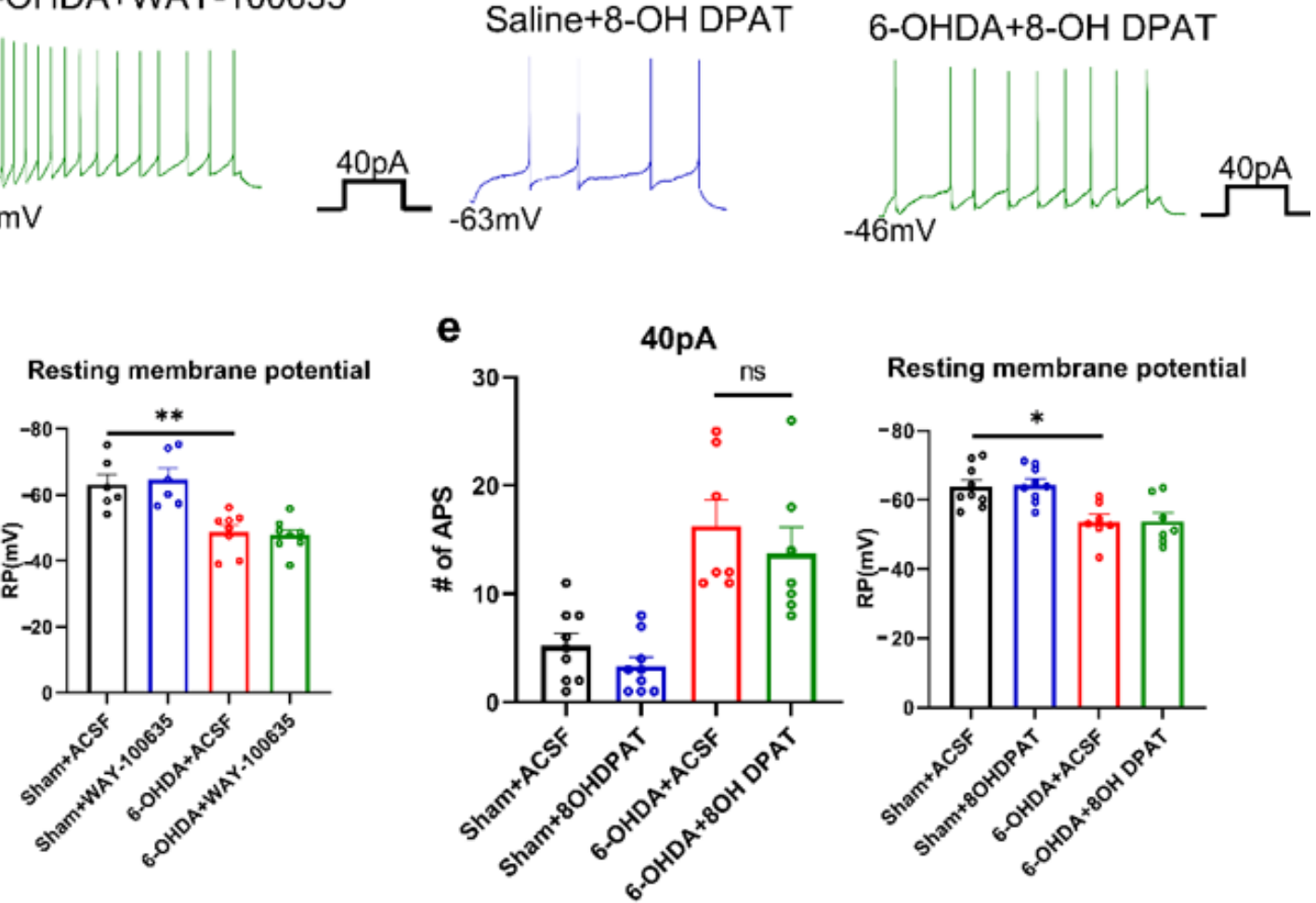

Figure 5

The effect of 5-HT1 agonist and antagonist on the excitability of SDH neurons

a, Representative current-clamp recordings showing firing evoked by $40 \mathrm{pA}$ current injection from an SDH neuron of a saline control rat (left panels) and that from an SDH neuron of a 6-OHDA-lesioned rat (right panels) in the absence (upper panels) and presence (middle panels) of WAY-100635 (10 $\mu \mathrm{M})$

b,WAY-100635 have no significant effect on AP frequency recorded in the SDH neurons of sham and 6OHDA rats at L4-L6. ( $n=9$ cells for sham rats and $n=7$ cells for $6-$ OHDA rats, $P>0.05$, one-way ANOVA).

c, Summarized data showing the mean resting membrane potential of the SDH neurons in the saline control rats and the 6-OHDA-lesioned rats with and without WAY-100635. ( $n=9$ cells for sham rats and $\mathrm{n}=7$ cells for $6-\mathrm{OHDA}$ rats, ${ }^{*} P<0.01$, one-way ANOVA).

d, Representative current-clamp recordings showing firing evoked by $40 \mathrm{pA}$ current injection from an SDH neuron of a saline control rat (left panels) and that from an SDH neuron of a 6-OHDA-lesioned rat (right panels) in the absence (upper panels) and presence (middle panels) of 8-OH DPAT (10 $\mu \mathrm{M})$ 
e,8-OH DPAT didn't alter AP frequency recorded in the SDH neurons of both sham and 6-OHDA rats at L4L6. ( $n=6$ cells for sham rats and $n=8$ cells for $6-$ OHDA rats, $P>0.05$, one-way ANOVA).

$\mathrm{f}$, Summarized data showing the mean resting membrane potential of the SDH neurons in the saline control rats and the 6-OHDA-lesioned rats with and without 8-OH DPAT. $(n=6$ cells for sham rats and $n=8$ cells for 6-OHDA rats, $* P<0.05$, one-way ANOVA).

a

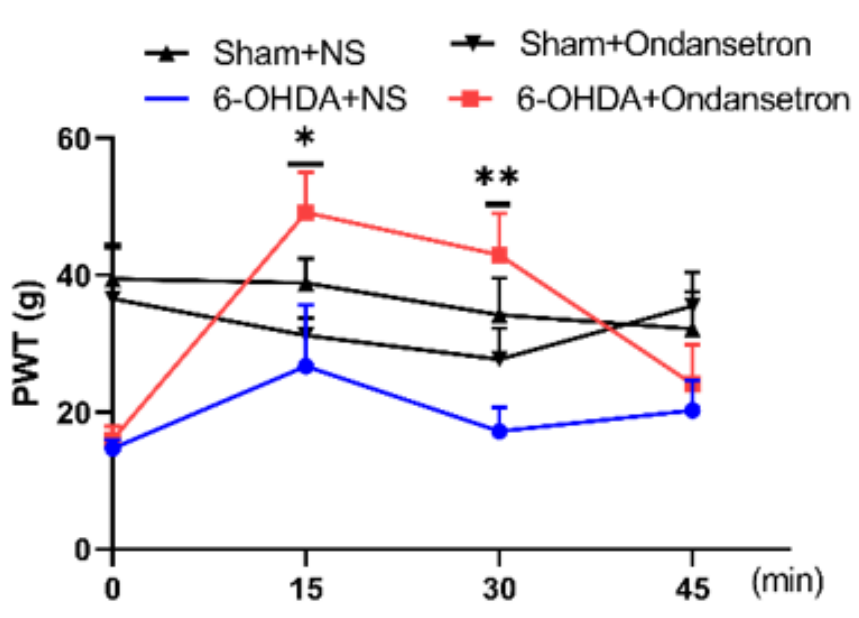

C

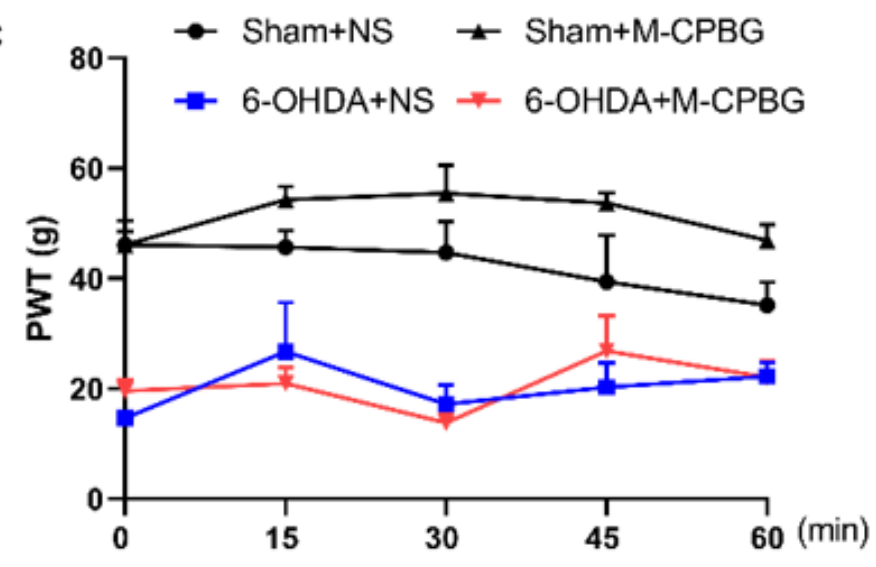

b
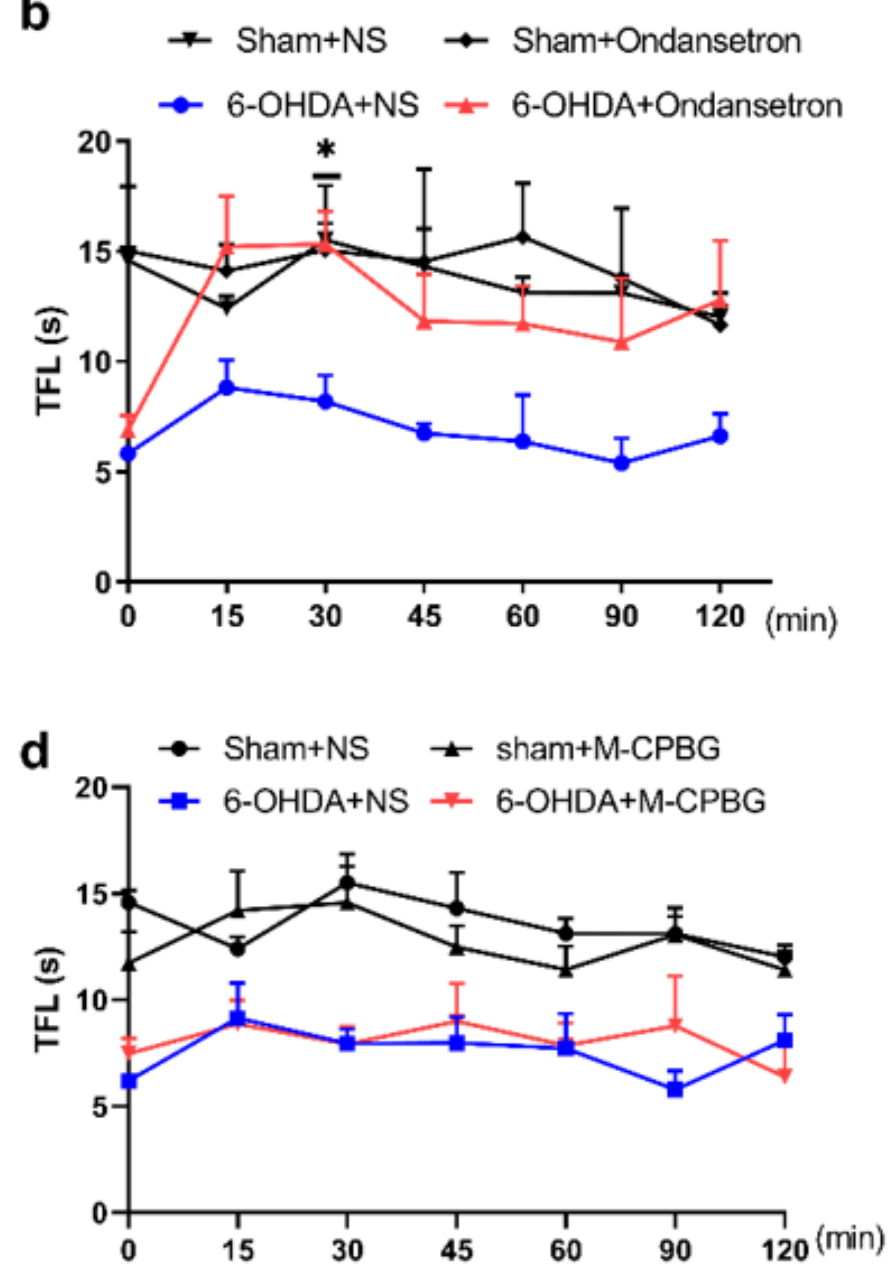

Figure 6

Effects of 5-HT3 receptor agonist and antagonist on thermal and mechanical hypersensitivity in 6-OHDAlesioned rats.

a-b, Intrathecal injection of ondansetron $(0.1 \mathrm{mg} / \mathrm{kg})$ significantly attenuated mechanical and thermal hypersensitivity in 6-OHDA rats. ( $\mathrm{n}=3-6$ for each group, ${ }^{\star *} P<0.01, * P<0.05$, two-way ANOVA).

c-d, Intrathecal injection of M-CPBG $(0.1 \mathrm{mg} / \mathrm{kg})$ did not inhibit mechanical and thermal hypersensitivity in 6-OHDA rats. ( $\mathrm{n}=3-7$ for each group, $P>0.05$, two-way ANOVA). 


\section{Figure 7}

Effects of 5-HT1A receptor agonist and antagonist on thermal and mechanical hypersensitivity in 6OHDA-lesioned rats.

$a-b$, Intrathecal injection of $8-\mathrm{OH}$ DPAT $(0.1 \mathrm{mg} / \mathrm{kg})$ has little effect on mechanical and thermal hypersensitivity in 6-OHDA rats. ( $n=5-8$ for each group, $P>0.05$, two-way ANOVA).

c-d, Intrathecal injection of WAY-100635(0.1 mg/ $\mathrm{kg})$ did not affect mechanical and thermal hypersensitivity in 6-OHDA rats. ( $\mathrm{n}=6-8$ for each group, $P>0.05$, two-way ANOVA). 